\title{
Analysis of Roll Steering for Solar Electric Propulsion Missions
}

Dylan M. Pederson and Jeffrey S. Hojnicki

Glenn Research Center, Cleveland, Ohio 


\section{NASA STI Program . . . in Profile}

Since its founding, NASA has been dedicated to the advancement of aeronautics and space science. The NASA Scientific and Technical Information (STI) program plays a key part in helping NASA maintain this important role.

The NASA STI Program operates under the auspices of the Agency Chief Information Officer. It collects, organizes, provides for archiving, and disseminates NASA's STI. The NASA STI program provides access to the NASA Aeronautics and Space Database and its public interface, the NASA Technical Reports Server, thus providing one of the largest collections of aeronautical and space science STI in the world. Results are published in both non-NASA channels and by NASA in the NASA STI Report Series, which includes the following report types:

- TECHNICAL PUBLICATION. Reports of completed research or a major significant phase of research that present the results of NASA programs and include extensive data or theoretical analysis. Includes compilations of significant scientific and technical data and information deemed to be of continuing reference value. NASA counterpart of peer-reviewed formal professional papers but has less stringent limitations on manuscript length and extent of graphic presentations.

- TECHNICAL MEMORANDUM. Scientific and technical findings that are preliminary or of specialized interest, e.g., quick release reports, working papers, and bibliographies that contain minimal annotation. Does not contain extensive analysis.

- CONTRACTOR REPORT. Scientific and technical findings by NASA-sponsored contractors and grantees.
- CONFERENCE PUBLICATION. Collected papers from scientific and technical conferences, symposia, seminars, or other meetings sponsored or cosponsored by NASA.

- SPECIAL PUBLICATION. Scientific, technical, or historical information from NASA programs, projects, and missions, often concerned with subjects having substantial public interest.

- TECHNICAL TRANSLATION. Englishlanguage translations of foreign scientific and technical material pertinent to NASA's mission.

Specialized services also include creating custom thesauri, building customized databases, organizing and publishing research results.

For more information about the NASA STI program, see the following:

- Access the NASA STI program home page at http://www.sti.nasa.gov

- E-mail your question to help@sti.nasa.gov

- Fax your question to the NASA STI Information Desk at 443-757-5803

- Phone the NASA STI Information Desk at 443-757-5802

- Write to: STI Information Desk NASA Center for AeroSpace Information 7115 Standard Drive Hanover, MD 21076-1320 
NASA/TM-2012-217683

\section{Analysis of Roll Steering for Solar Electric Propulsion Missions}

Dylan M. Pederson and Jeffrey S. Hojnicki

Glenn Research Center, Cleveland, Ohio

Prepared for the

48th Joint Propulsion Conference and Exhibit

cosponsored by AIAA, ASME, SAE, ASEE

Atlanta, Georgia, July 29 to August 1, 2012

National Aeronautics and

Space Administration

Glenn Research Center

Cleveland, Ohio 44135 


\section{Acknowledgments}

Dylan Pederson and Jeffrey Hojnicki thank the Power Systems Engineering branch at NASA Glenn Research Center for support in this study. Special thanks are due to Thomas Kerslake and Robert Klimek for guidance through this project. Mr. Pederson also thanks the Undergraduate Student Research Program and the Universities Space Research Association for providing an opportunity to work and learn at NASA Glenn Research Center.

This report contains preliminary findings, subject to revision as analysis proceeds.

Level of Review: This material has been technically reviewed by technical management.

Available from

NASA Center for Aerospace Information 7115 Standard Drive

Hanover, MD 21076-1320
National Technical Information Service 5301 Shawnee Road Alexandria, VA 22312

Available electronically at http://www.sti.nasa.gov 


\title{
Analysis of Roll Steering for Solar Electric Propulsion Missions
}

\author{
Dylan M. Pederson and Jeffrey S. Hojnicki \\ National Aeronautics and Space Administration \\ Glenn Research Center \\ Cleveland, Ohio 44135
}

\begin{abstract}
Nothing is more vital to a spacecraft than power. Solar Electric Propulsion (SEP) uses that power to provide a safe, reliable, and, most importantly, fuel efficient means to propel a spacecraft to its destination. The power performance of an SEP vehicle's solar arrays and electrical power system (EPS) is largely influenced by the environment in which the spacecraft is operating. One of the most important factors that determines solar array power performance is how directly the arrays are pointed to the sun. To get the most power from the solar arrays, the obvious solution is to point them directly at the sun at all times. Doing so is not a problem in deep space, as the environment and pointing conditions that a spacecraft faces are fairly constant and are easy to accommodate, if necessary. However, large and sometimes rapid variations in environmental and pointing conditions are experienced by Earth orbiting spacecraft. SEP spacecraft also have the additional constraint of needing to keep the thrust vector aligned with the velocity vector. Thus, it is important to analyze solar array power performance for any vehicle that spends an extended amount of time orbiting the Earth, and to determine how much off-pointing can be tolerated to produce the required power for a given spacecraft. This paper documents the benefits and drawbacks of "perfectly pointing" the solar arrays of an SEP spacecraft spiraling from Earth orbit, and how this might be accomplished. Benefits and drawbacks are defined in terms of vehicle mass, power, volume, complexity, and cost. This paper will also look at the application of various solar array pointing methods to future missions. One such pointing method of interest is called "roll steering". Roll steering involves rolling the entire vehicle twice each orbit. Roll steering, combined with solar array gimbal tracking, is used to point the solar arrays perfectly towards the sun at all points in the orbit, while keeping the vehicle thrusters aligned in the velocity direction. Roll steering is particularly attractive for a recently proposed mission that involves a spiral trajectory from low Earth orbit (LEO) to the Earth-Moon Lagrange Point 1 (E-M L1). During the spiral, the spacecraft will spend over 300 days experiencing the full spectrum of near-earth environments and solar array pointing conditions. An extensive study of the application of SEP (and roll steering) to this spiral mission is included, highlighting the ultimate goal of reduced vehicle cost and mass. Tools used for this analysis include the Systems Power Analysis for Capability Evaluation (Refs. 1 and 2) (SPACE) electrical power systems code, and SEP trajectory simulation tools developed at NASA Glenn Research Center.
\end{abstract}

\section{Nomenclature}

$\beta \quad$ angle between the vector from Earth to orbit noon and the Earth-Sun vector

SEP Solar Electric Propulsion

EPS Electrical Power System

HET Hall Effect Thruster

RAAN Right Ascension of the Ascending Node

ISS International Space Station

CMG Control Moment Gyroscope

E-M L1 Earth-Moon Lagrange Point 1

SPACE System Power Analysis for Capability Evaluation 


\section{Introduction}

Spacecraft that employ solar electric propulsion (SEP) for primary propulsion are already flying in interplanetary space (e.g., Deep Space 1, Dawn) and have proven that SEP is a key enabling technology for some solar system exploration missions. SEP uses solar arrays to generate power for electric thrusters. These thrusters, which could be Hall effect thrusters (HETs) or ion thrusters, expel ionized xenon gas to generate thrust. Present HET capability provides a very small amount of thrust $(0.5 \mathrm{~N}-3 \mathrm{~N})$ which slowly accelerates the spacecraft to high speeds. Although HETs are very efficient, their low thrust means it takes a long time to reach sufficient speeds. NASA is now investigating applications that use the HET thrusters to propel a spacecraft from low Earth orbit (LEO) and escape Earth's gravitational pull. The low thrust of the SEP system necessitates a trajectory which spirals slowly from LEO out to deeper space. Because of the extended trip time and increasing altitudes during the spiral, the spacecraft making the trip will experience the full spectrum of space environments from low to high Earth orbit.

Some of the most significant challenges faced during the spiral involve variations in solar flux, radiation dose, atomic oxygen, atmospheric density, temperature, and $\beta$ angle. Variations in these parameters have a great impact on the power production of the spacecraft's solar arrays. This, in turn can have a significant impact on the HET specific impulse and thrust, and therefore, on the total spiral trip time. One variable of particular interest to this analysis is the solar $\beta$ angle (Fig. 1). The $\beta$ angle varies throughout the year because of the Earth's movement around the Sun and from precession of the longitude of the ascending node of the spacecraft's orbit. Additionally, for spiral trajectories, the rate of change of the $\beta$ angle changes as the altitude increases. This gives rise to an interesting $\beta$ angle profile throughout the trajectory. The $\beta$ angle profile depends on many different variables, but a typical profile for a spiral trajectory is shown in Figure 2.

The $\beta$ profile depends on the right ascension of the ascending node (RAAN) of the spacecraft's orbit at the beginning of the spiral. After the spacecraft reaches a high enough altitude, the RAAN no longer varies from Earth's oblateness. Depending on when the RAAN precession rate becomes negligible, the spacecraft could experience large oscillations in $\beta\left( \pm 50^{\circ}\right)$ or smaller oscillations (or even no oscillations at all). Some possible $\beta$ profiles for this spiral mission are shown in Figure 3.

The $\beta$ angle is important to spacecraft power because it affects the amount of off-pointing a solar array will experience, if left uncompensated. A typical spacecraft will consist of a bus, with two solar array wings mounted collinear with one of the spacecraft's principle axes. The wings typically are pointed by single axis gimbals that are used to compensate for once-per-orbit revolution of the spacecraft around the Earth (i.e., so-called alpha pointing). Compensation for the $\beta$ angle is either not performed (i.e., accept off-pointing), or handled by varying the attitude of the spacecraft. Since an SEP spacecraft must also maintain the vehicle's thrust axis in a specific direction, there are limited attitudes that can be flown.

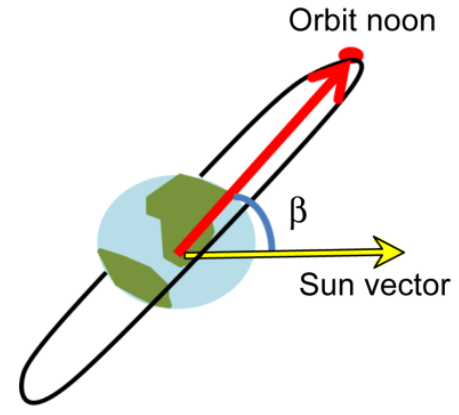

Figure 1.-Solar $\beta$ angle.

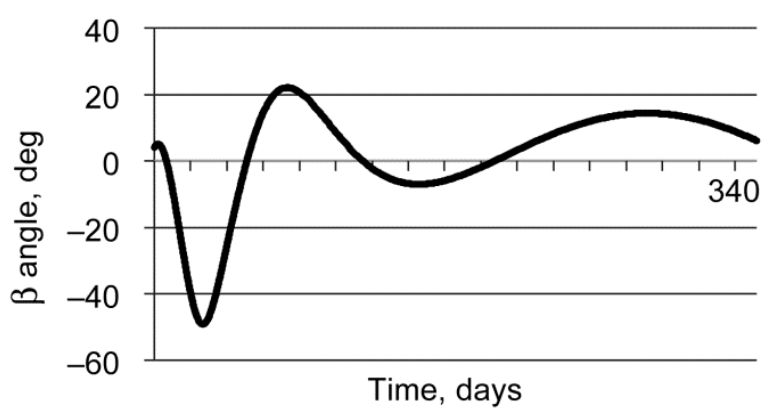

Figure 2.-Typical $\beta$ angle profile for spiral. 


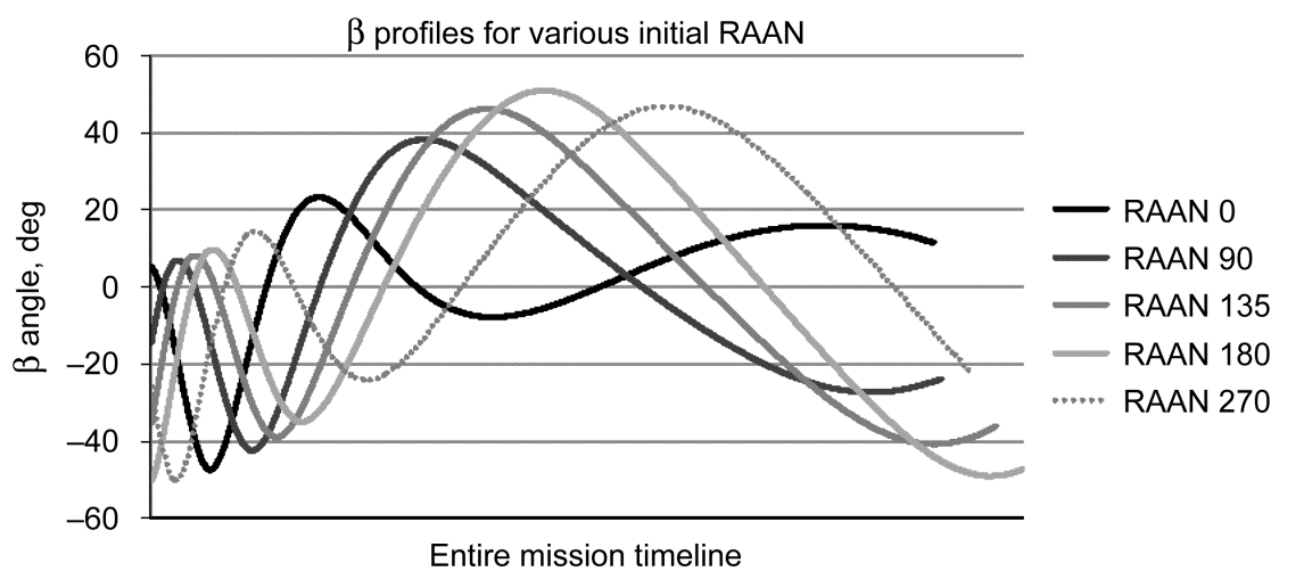

Figure 3.-Spiral $\beta$ profiles with various initial orbit Right Ascension of the Ascending Node (RAAN).

Therefore, a solar array with a single axis gimbal, barring any other corrections, will experience an offpointing equivalent to the $\beta$ angle (e.g., for $20^{\circ} \beta$ angle, the solar array will suffer $20^{\circ}$ off-pointing; for $30^{\circ} \beta, 30^{\circ}$ off-pointing, and so on). When the solar array is off-pointed, it loses power because it is absorbing a smaller area of sunlight. The solar array is said to suffer from "cosine power loss". This is because the power with respect to $\beta$ is closely approximated by

$$
P(\beta) \approx P(0) \cos (\beta)
$$

where $P(0)$ is the power produced at a $\beta$ angle of $0^{\circ}$. In other words, maximum power is achieved at $\beta=0^{\circ}$. Clearly, if there is a way to eliminate off-pointing completely, it could provide a boost in power production for such a spiral mission which would decrease the trip time through the spiral.

\section{Power Benefit of Perfect Pointing}

A solar array is said to be perfectly pointing when it is adjusted to point directly towards the sun at all times (i.e., total elimination of off-pointing, within the accuracy that the attitude control, structures and mechanisms allow). For any mission that will experience a wide range of $\beta$ angles, it is important to know exactly how much perfect pointing might improve power generation compared to allowing off-pointing. To determine the effect that perfect pointing has on spacecraft power, analyses were performed with the SPACE (Refs. 1 and 2) power model to study orbits with perfectly pointed solar arrays and orbits with off-pointed solar arrays. Relevant variables for the spiral mission power are orbital altitude and $\beta$ angle. Altitude is important because at higher altitudes, the time spent in insolation during an orbit increases, which improves overall energy production. The $\beta$ angle is important for reasons mentioned earlier.

According to SPACE analyses, although the magnitude of the power gain from perfect pointing (compared to off-pointing) does depend on orbit altitude, the percentage gain does not. That is, the benefits of perfect pointing are similar at all altitudes. This makes sense intuitively, as the cosine power rule does not depend on orbital altitude. Therefore, just one altitude was used for further examination.

As Figure 4 indicates, perfect pointing is most beneficial at higher $\beta$ angles. Perfect pointing gives just 1 percent power gain on orbit average (compared to off-pointed power generation) at a $10^{\circ} \beta$ angle. On the other hand, at large $\beta$ angles perfect pointing can give well over 50 percent more power than offpointing. The $\beta$ profile for this mission shows that the spacecraft will experience $\beta$ angles from $-52^{\circ}$ up to $+52^{\circ}$. Thus, a significant amount of power can be gained from perfect pointing throughout the spiral. 

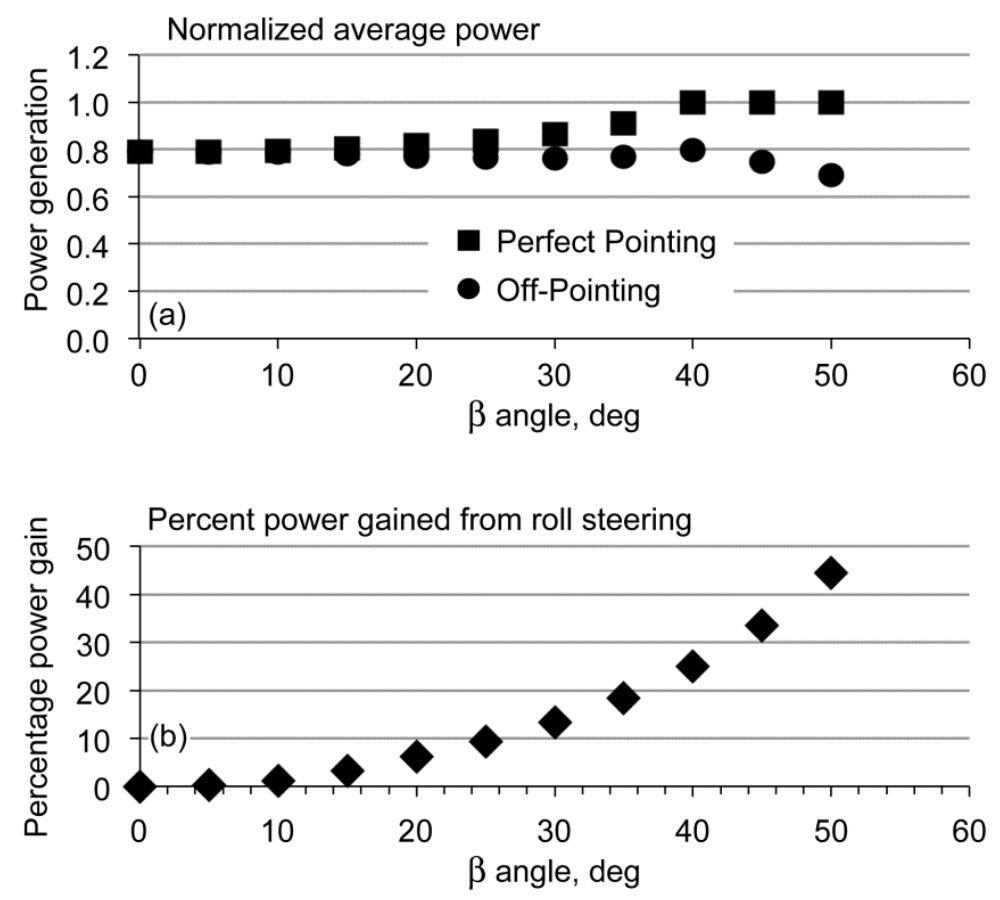

Figure 4.-(a) Comparison of average orbital power for a $3900 \mathrm{~km}$ altitude orbit. (b) Percentage power gain from perfect pointing versus $\beta$ angle at $3900 \mathrm{~km}$ altitude.

\section{Options to Compensate for Off-Pointing?}

Spacecraft have been able to achieve perfect pointing in the past using a variety of methods. For example, the International Space Station (ISS) solar structure has two gimbals for each solar array. The two gimbal rotation axes are orthogonal to each other, allowing for perfect pointing at all times (there are some complications to this that will be discussed later). Other methods are available, and each has its drawbacks. This study will consider the following methods.

\section{Larger Solar Arrays}

Perhaps the most obvious way to gain more power throughout a mission (and therefore speed up the trip) has nothing to do with pointing, but instead is to make the solar arrays bigger. The approach is simple: by making the solar arrays 10 percent bigger, then 10 percent more power is available at all $\beta$ angles. The obvious downside is that the solar array still suffers from cosine power loss, but now on a larger scale! Also, the electrical power system (EPS), thermal control system (TCS), and spacecraft structure must be sized accordingly for a larger solar array. In general, this means that spacecraft as a whole will grow in mass. In most cases, a spacecraft's mass is limited by the lift capabilities of its launch vehicle. If the spacecraft outgrows the launch vehicle, then the mission may need to consider a larger (and more expensive) launch vehicle to accommodate the spacecraft.

In addition to mass concerns, making a solar array larger is expensive. Solar cell production and installation achieves limited "economies of scale". This is because, presently, solar cell production is mostly a batch process and the installation of the cells onto the solar array wing involves manual processing. Larger solar array sizes can also be more difficult (and costly) to build, test and integrate with the spacecraft and to fit inside the launch vehicle fairing. So, in general, making a solar array larger is undesirable. 


\section{Two-Axis Tracking}

The largest and most powerful solar array wings ever flown in space are on the ISS. As mentioned earlier, the ISS solar array structure provides two gimbals for each solar array. This method of solar array pointing is called two-axis tracking, because the solar arrays can rotate along two orthogonal axes.

\section{Case I-ISS Model}

The ISS solar arrays all have one rotation axis in common, controlled by the solar alpha rotary joint (SARJ). Additionally, every solar array has a second gimbal, known as a beta gimbal that rotates the array along its individual axis perpendicular to the alpha rotation axis. These two gimbals allow each array to point perfectly (within tolerance) towards the sun. The weight of each Beta gimbal is approximately $323 \mathrm{~kg}$, while the weight of the SARJ is $1161 \mathrm{~kg}$. This arrangement is considered mass prohibitive for an SEP spiral mission, and the challenge of packaging such a structure into a single launch vehicle may be even more challenging.

\section{Case II-Dumbo Model}

An alternative method of two-axis tracking is to have two adjacent gimbals for each wing. One gimbal would be stacked upon the other, where the wing meets the vehicle body. This model is named after its Dumbo-like "flapping" of the solar array wings. This would provide perfect pointing without the need for a large alpha truss structure. One concern with this method is that when the wings are tracking the sun, it is possible for the center of mass of the vehicle to shift, causing the vehicle to pitch while the HETs are running. This would necessitate the ability to gimbal the thrusters continuously as the solar arrays are tracking, leading to propulsion performance losses and hence, longer spiral mission trip times. Additionally, while the arrays are tracking, array shadowing may be more likely, plus the vehicle designers will have to be conscious to prevent the wings from bumping into the vehicle body. Such complexity in spacecraft operation is undesirable. Further attention should be given to the feasibility of this method, but that is not the purpose of this study.

\section{Roll Steering}

A solar array pointing method known as "roll steering" is achieved by rolling the spacecraft about the velocity vector to achieve the same pointing effectiveness as a second gimbal. This requires rolling the spacecraft twice per orbit while maintaining the thrust vector closely collinear with the velocity vector. This allows the solar arrays to perfectly point with just one gimbal. To roll a large vehicle, control moment gyroscopes (CMGs) are preferred over reaction wheels or magnetic torquers because CMGs provide the large torque and momentum storage capability needed for such a maneuver. Roll steering provides perfect pointing, and thus reaps the power benefits outlined earlier.

The number of CMGs required to implement full roll steering will depend on the total vehicle moment of inertia about its roll axis and the torque capability of the CMGs. Torque (as opposed to momentum) is the limiting factor in determining how many CMGs are needed to fully roll steer, because at low $\beta$ angles the vehicle is required to roll at a large rate that is sometimes referred to as a "snap" roll (as opposed to a gradual roll). These snap rolls can require a large torque to complete. The drawbacks of full roll steering include a potentially large mass penalty for the CMGs and increased operational complexity. 


\section{Roll Switch}

Roll switching is a variation of roll steering that tolerates a certain amount of off-pointing. In other words, the vehicle only rolls when the $\beta$ angle is greater than a specified angle. This is done to take advantage of the large power benefit from rolling at higher $\beta$ angles, and to avoid the extra mass of CMGs required to roll at lower $\beta$ angles. The cross-over $\beta$ angle (between roll steering and not) will depend on the moment of inertia of a specified vehicle and its CMG capabilities.

\section{Application to an Asteroid Mission}

To compare the alternatives for solar array pointing, each method was separately applied to a proposed mission vehicle. The vehicle specifications came from the Human Exploration Framework Team (HEFT) and the Collaborative Modeling for Parametric Assessment of Space Systems (COMPASS) team at NASA Glenn Research Center. COMPASS and HEFT have laid out and analyzed a proposed human mission to the asteroid 2008-EV5 (henceforth referred to as the EV5 mission) that heavily uses SEP technology (Refs. 3 to 5). This mission involves a spiral trajectory carrying cargo from low-Earth orbit to the Earth-Moon Lagrange point 1 (E-M L1) followed by a heliocentric trajectory carrying crew to the asteroid, both using a 300-kW-class SEP vehicle. This analysis uses the EV5 SEP vehicle as a baseline for comparison.

To fairly evaluate roll steering and its alternatives, it is necessary to compare to the base case of not rolling the vehicle and accepting off-pointing. A quantitative comparison was performed with an SEP low thrust trajectory simulation tool when possible. Otherwise, qualitative comparisons were performed where the relative performance of the various options was estimated, since a detailed assessment of those factors could not be performed for this analysis. The following information is summarized in Table 1.

\section{Larger Solar Arrays}

Scaling the $300 \mathrm{~kW}$ solar arrays on the EV5 vehicle up by 10 percent would add around $300 \mathrm{~kg}$ of mass to the vehicle, taking into account resizing of the EPS, TCS, and vehicle structure. The real problem with the larger arrays is that they add cost to the most expensive part of the vehicle. Figure 6 shows that the most expensive part of an SEP vehicle is the solar array. This is why it is impractical to make larger solar arrays.

TABLE 1.-COMPARISON OF ALL METHODS TO THE NO ROLL STEERING CASE

\begin{tabular}{|l|c|c|c|c|c|c|c|}
\hline \multicolumn{1}{|c|}{$\begin{array}{c}\text { Pointing } \\
\text { method }\end{array}$} & $\begin{array}{c}\text { Vehicle } \\
\text { mass, } \\
\mathrm{kg}\end{array}$ & $\begin{array}{c}\text { Array } \\
\text { power }^{\mathrm{a}} \\
\mathrm{W}\end{array}$ & $\begin{array}{c}\text { Flight } \\
\text { hardware } \\
\text { volume }\end{array}$ & $\begin{array}{c}\text { Flight software } \\
\text { development }\end{array}$ & $\begin{array}{c}\text { Systems } \\
\text { complexity }\end{array}$ & $\begin{array}{c}\text { Vehicle } \\
\text { cost }\end{array}$ & $\begin{array}{c}\text { Est. trip time } \\
\text { to E-M L1, } \\
\text { days }\end{array}$ \\
\hline $\begin{array}{l}\text { No roll } \\
\text { steering }\end{array}$ & 77424 & ---- & Low & Low & Low & $\$ \$$ & 321 \\
\hline Roll steering & 79056 & $+14 \%$ & Med & High & Med & $\$ \$ \$$ & 295 \\
\hline $\begin{array}{l}\text { Upsize solar } \\
\text { arrays } \\
10 \text { percent }\end{array}$ & 77700 & $+10 \%$ & High & N/A & High & $\$ \$ \$ \$ \$$ & 290 \\
\hline $\begin{array}{l}\text { Two axis } \\
\text { tracking- } \\
\text { ISS model }\end{array}$ & $79000+$ & $+14 \%$ & High & High & & & \\
\hline $\begin{array}{l}\text { Roll switch at } \\
\beta=21^{\circ}\end{array}$ & 78240 & $+13 \%$ & Low & High & Med & $\$ \$$ & 294 \\
\hline
\end{tabular}

${ }^{a}$ All power numbers are in comparison to the case of no roll steering. 


\section{Two-Axis Tracking}

To two-axis track, this $300 \mathrm{~kW}$ class SEP vehicle would require eight beta gimbals and two structures equivalent to the ISS SARJ. The solar arrays on the $300 \mathrm{~kW}$ vehicle are smaller than the ISS solar arrays, so the required gimbal size would be smaller. Each beta gimbal is estimated to be around $215 \mathrm{~kg}$ (Ref. 6), totaling to $1720 \mathrm{~kg}$ (not including the alpha gimbal and structure)!

\section{Full Roll Steering}

This study assumes that the same CMGs as are used on the ISS will be used for the EV5 vehicle to perform full roll steering, because the ISS CMGs are flight proven, and are approximately the required capability needed for the SEP mission. The ISS CMGs can provide $4760 \mathrm{Nms}$ of momentum storage and $258 \mathrm{Nm}$ of torque output. The torque and momentum required for roll steering the $300-\mathrm{kW}$-class SEP vehicle are shown in Figure 5. For this vehicle to roll at almost all $\beta$ angles ( $5^{\circ}$ and above), a total of 6 ISS CMGs are necessary (5 for rolling, and 1 for redundancy). The CMGs add $1632 \mathrm{~kg}$ of mass to the vehicle, and draw approximately $900 \mathrm{~W}$ of power (averaged over one orbit).

\section{Roll Switching}

As mentioned earlier, the optimal cross-over $\beta$ depends on the vehicle requirements. For this $300 \mathrm{~kW}$ SEP vehicle, the cross-over $\beta$ will be $21^{\circ}$ so that just 3 CMGs are needed ( 2 for rolling, and 1 for redundancy). This $\beta$ was found by numerically optimizing the balance between extra mass from CMGs and extra power from rolling. Compared to full roll steering, this method cuts the weight and power load from the CMGs in half to $816 \mathrm{~kg}$ and $450 \mathrm{~W}$. It is fairly evident that full roll steering and two-axis tracking are the worst two alternatives overall. In fact, from a quick glance at Figure 6, no roll steering may seem like the best option. But, the "best" option really depends on what the mission is trying to accomplish. If the spacecraft is trying to reach its destination as quickly as possible (as a communications satellite might do, to make profits as soon as possible) then it may be best to simply have larger arrays.
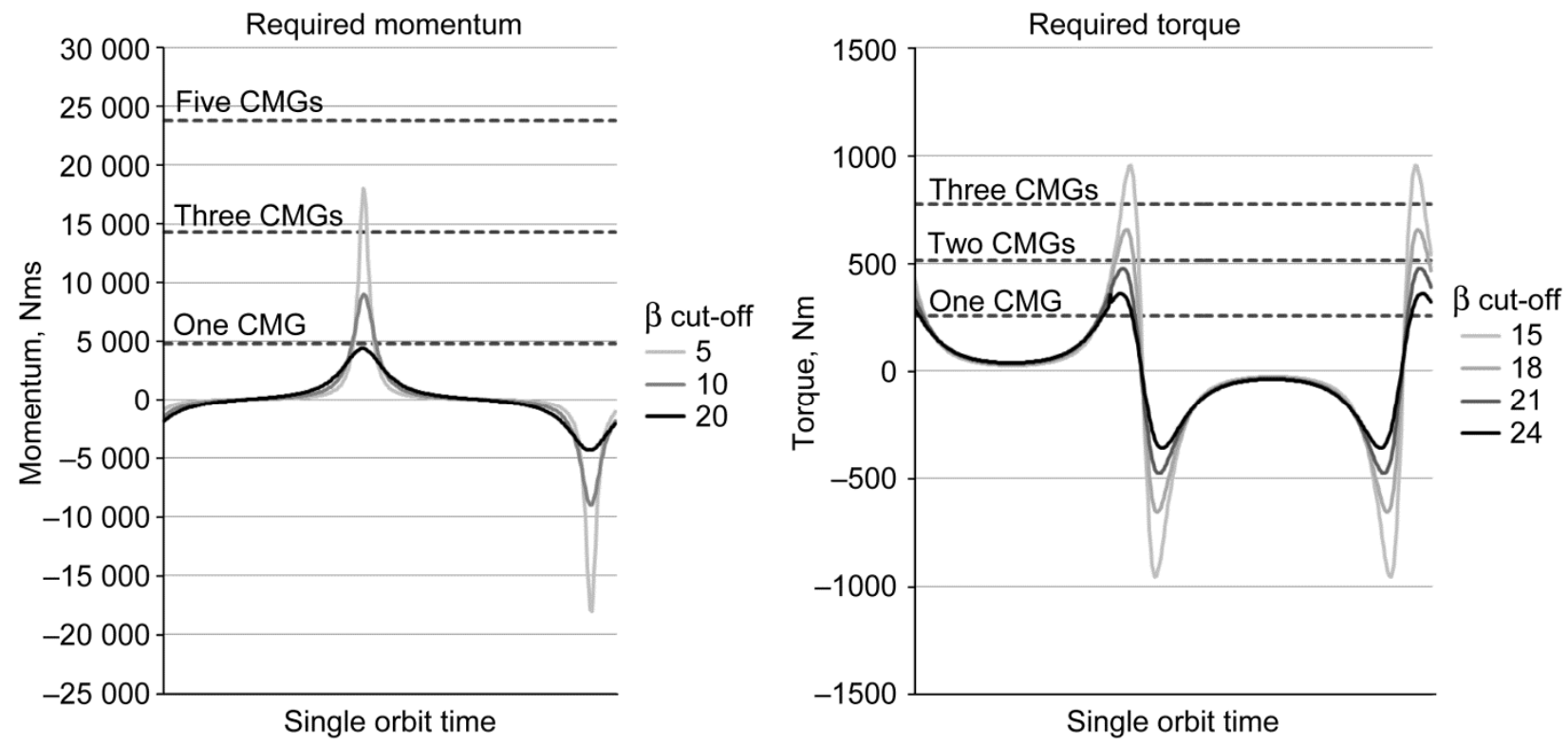

Figure 5.-Torque and momentum required for roll steering the $300 \mathrm{~kW}$ class SEP vehicle through a $400 \mathrm{~km}$ altitude orbit at various $\beta$ s. CMG capabilities are also included as shown by the dashed lines. 


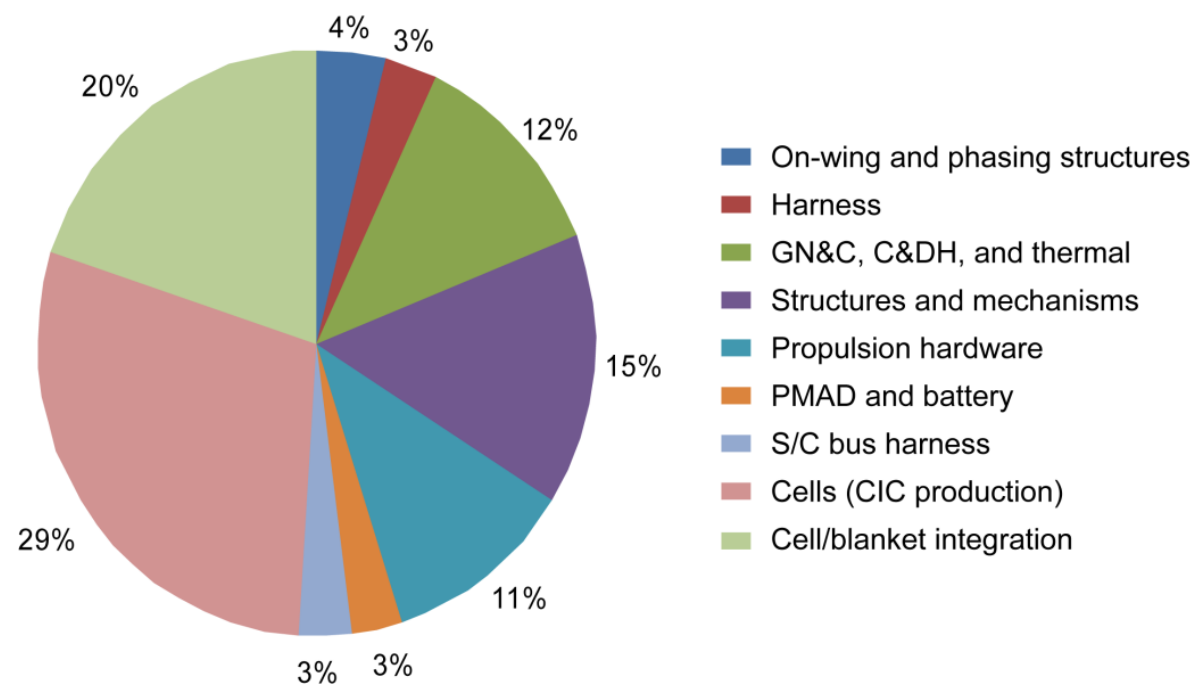

Figure 6.-A large percentage (Ref. 6) of the cost (development plus flight hardware cost) of a SEP vehicle is in its solar arrays. There are additional costs associated with systems integration (flight software, testing, etc.).

TABLE 2.-DIRECT COMPARISON OF NO ROLL STEERING AND ROLL SWITCHING WITH RESIZED ARRAYS (FOR A SPIRAL WITH AN INITIAL RAAN OF $110^{\circ}$ AND A START DATE OF JANUARY 1)

\begin{tabular}{|l|c|c|c|c|c|c|c|}
\hline $\begin{array}{c}\text { Pointing } \\
\text { method }\end{array}$ & $\begin{array}{c}\text { Vehicle } \\
\text { mass, } \\
\mathrm{kg}\end{array}$ & $\begin{array}{c}\text { Array } \\
\text { power }\end{array}$ & $\begin{array}{c}\text { Flight } \\
\text { hardware } \\
\text { volume }\end{array}$ & $\begin{array}{c}\text { Flight software } \\
\text { development }\end{array}$ & $\begin{array}{c}\text { Systems } \\
\text { complexity }\end{array}$ & $\begin{array}{c}\text { Vehicle } \\
\text { cost }\end{array}$ & $\begin{array}{c}\text { Est. trip } \\
\text { time to } \\
\text { E-M L1, } \\
\text { days }\end{array}$ \\
\hline $\begin{array}{l}\text { No roll } \\
\text { steering }\end{array}$ & 77424 & $\begin{array}{c}300 \mathrm{~kW} \\
\text { EOL }\end{array}$ & High & Low & Low & $\$ \$ \$ \$$ & 321 \\
\hline $\begin{array}{l}\text { Resized } \\
\text { arrays with } \\
\text { roll switch } \\
\text { at } \beta=21^{\circ}\end{array}$ & 78102 & $\begin{array}{c}270 \mathrm{~kW} \\
\text { EOL }\end{array}$ & Lower & High & Med & $\$$ & 319 \\
\hline
\end{tabular}

However, "best" in the context of an SEP spacecraft for the given mission is defined as the lowest cost and mass. The spiral mission is not concerned with trip time as long as it is within the mission time frame. In fact, if the spacecraft gets to E-M L1 quickly then it will potentially have to use more propellant to maintain its "halo" orbit for a longer period of time while waiting to rendezvous with other mission elements. Thus, upsizing the solar arrays is really not a good option for this mission.

So far, three options can be eliminated; larger solar arrays are not good because they do not fit the definition of "best" as we define it here, and two-axis tracking and full roll steering are trumped by the lighter weight and lower cost of roll switching. To get a fair, head-to-head comparison of the remaining options (roll switch and no roll), the factors that are unimportant to this mission must be evened out. In other words, the trip time of the roll switch case and the no roll case must be the same to get a fair comparison of cost and mass. The solar array power levels and propellant loads for each of the two options were adjusted until trajectory analyses showed the trip times of each case matched to $320 \pm 1$ days. The resulting effect on vehicle cost and mass are shown in Table 2.

From this perspective, roll switching looks more attractive, as it saves cost by allowing for smaller solar arrays. The mass of the vehicle is heavier with roll switch, but still stays within the launch vehicle constraint of 80 metric tons. This example was the average case (with an initial RAAN of $110^{\circ}$ ), but depending on initial orbital conditions, the power savings can vary from 10 to $50 \mathrm{~kW}$. Even in the worst case, reducing the power required by $10 \mathrm{~kW}$ can still save millions of dollars on the solar arrays. In addition, the size of the TCS and EPS can probably be downsized because of the smaller arrays, saving additional mass and cost. 


\section{Conclusion}

The authors conclude that roll switching can offer one of two benefits, depending on your objective. For the EV5 asteroid mission, roll switching can be used to allow smaller solar arrays, and thus save money on the spacecraft. Additionally, roll switching can be used to get to a destination more quickly, simply as a result of more efficient collection of solar power. Larger arrays can also get a spacecraft to its destination faster, but it is more cost effective to pay for relatively cheap CMGs than to pay for larger arrays.

In general, it is not worth the extra CMG mass to fully roll steer at all $\beta$ angles. "Roll switching" is the better alternative to save money and mass on the vehicle. The overall effectiveness of roll switching will depend on the mission $\beta$ profile. For the example mission, even in the most favorable case (for solar array pointing), the spacecraft can reduce the size of its solar arrays by 3 percent with roll switching.

\section{References}

1. Hojnicki, J.S., et al., "Space Station Freedom Electrical Performance Model,” NASA TM-106395, $28^{\text {th }}$ Intersociety Energy Conversion Engineering Conference, 1993.

2. Jannette, A.G., et al., "Validation of International Space Station Electrical Performance Model via On-Orbit Telemetry,” IECEC-2002-20007, 37 ${ }^{\text {th }}$ Intersociety Energy Conversion Engineering Conference, 2002.

3. Brophy, J.R., et al., "300-kW Solar Electric Propulsion System Configuration for Human Exploration of Near-Earth Asteroids,” AIAA-2011-5514, 47th AIAA/ASME/SAE/ASEE Joint Propulsion Conference \& Exhibit, San Diego, California, July 31, 2011.

4. Hoffman, D.J., et al., "Concept Design of High Power Solar Electric Propulsion Vehicles for a Human Exploration,” IAC-11-D2.3.5, $62^{\text {nd }}$ International Astronomical Conference, Cape Town, South Africa, October 3-7, 2011.

5. Capadona, L.A., et al., "Feasibility of Large High-Powered Solar Electric Propulsion Vehicles: Issues and Solutions," AIAA-2011-7251, Space 2011 Conference \& Exposition, Long Beach, California, September 27-29, 2011.

6. Mercer, C.R., et al., "Benefits of Power and Propulsion Technology for a Piloted Electric Vehicle to an Asteroid,” AIAA-2011-7252, Space 2011 Conference \& Exposition, Long Beach, California, September 27-29, 2011. 
The public reporting burden for this collection of information is estimated to average 1 hour per response, including the time for reviewing instructions, searching existing data sources, gathering and maintaining the data needed, and completing and reviewing the collection of information. Send comments regarding this burden estimate or any other aspect of this collection of information, including suggestions for reducing this burden, to Department of Defense, Washington Headquarters Services, Directorate for Information Operations and Reports (0704-0188), 1215 Jefferson Davis Highway, Suite 1204, Arlington, VA 22202-4302.

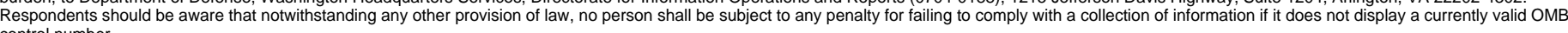

PLEASE DO NOT RETURN YOUR FORM TO THE ABOVE ADDRESS.

\begin{tabular}{|l|l|l}
\hline 1. REPORT DATE (DD-MM- $Y Y Y Y)$ & 2. REPORT TYPE & 3. DATES COVERED (FrOm - To)
\end{tabular}

01-08-2012

\section{TITLE AND SUBTITLE}

Technical Memorandum

Analysis of Roll Steering for Solar Electric Propulsion Missions

5a. CONTRACT NUMBER

5b. GRANT NUMBER

5c. PROGRAM ELEMENT NUMBER

6. AUTHOR(S)

Pederson, Dylan, M.; Hojnicki, Jeffrey, S. 5d. PROJECT NUMBER

5e. TASK NUMBER

5f. WORK UNIT NUMBER

WBS 272725.01.04.01

8. PERFORMING ORGANIZATION

REPORT NUMBER

E-18366
National Aeronautics and Space Administration

John H. Glenn Research Center at Lewis Field

Cleveland, Ohio 44135-3191

\section{SPONSORING/MONITORING AGENCY NAME(S) AND ADDRESS(ES)}

National Aeronautics and Space Administration

Washington, DC 20546-0001

\section{SPONSORING/MONITOR'S} ACRONYM(S)

NASA

11. SPONSORING/MONITORING REPORT NUMBER

NASA/TM-2012-217683

\section{DISTRIBUTIONIAVAILABILITY STATEMENT}

Unclassified-Unlimited

Subject Category: 20

Available electronically at http://www.sti.nasa.gov

This publication is available from the NASA Center for AeroSpace Information, 443-757-5802

\section{SUPPLEMENTARY NOTES}

\section{ABSTRACT}

Nothing is more vital to a spacecraft than power. Solar Electric Propulsion (SEP) uses that power to provide a safe, reliable, and, most importantly, fuel efficient means to propel a spacecraft to its destination. The power performance of an SEP vehicle's solar arrays and electrical power system (EPS) is largely influenced by the environment in which the spacecraft is operating. One of the most important factors that determines solar array power performance is how directly the arrays are pointed to the sun. To get the most power from the solar arrays, the obvious solution is to point them directly at the sun at all times. Doing so is not a problem in deep space, as the environment and pointing conditions that a spacecraft faces are fairly constant and are easy to accommodate, if necessary. However, large and sometimes rapid variations in environmental and pointing conditions are experienced by Earth orbiting spacecraft. SEP spacecraft also have the additional constraint of needing to keep the thrust vector aligned with the velocity vector. Thus, it is important to analyze solar array power performance for any vehicle that spends an extended amount of time orbiting the Earth, and to determine how much offpointing can be tolerated to produce the required power for a given spacecraft. This paper documents the benefits and drawbacks of "perfectly pointing" the solar arrays of an SEP spacecraft spiraling from Earth orbit, and how this might be accomplished. Benefits and drawbacks are defined in terms of vehicle mass, power, volume, complexity, and cost. This paper will also look at the application of various solar array pointing methods to future missions. One such pointing method of interest is called "roll steering". Roll steering involves rolling the entire vehicle twice each orbit. Roll steering, combined with solar array gimbal tracking, is used to point the solar arrays perfectly towards the sun

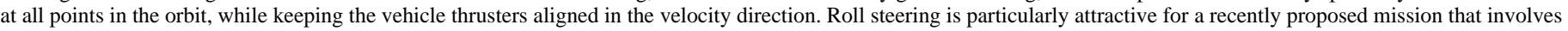
a spiral trajectory from low Earth orbit (LEO) to the Earth-Moon Lagrange Point 1 (E-M L1). During the spiral, the spacecraft will spend over 300 days experiencing the full spectrum of near-earth environments and solar array pointing conditions. An extensive study of the application of SEP (and roll steering) to this spiral mission is included, highlighting the ultimate goal of reduced vehicle cost and mass. Tools used for this analysis include the Systems Power Analysis for Capability Evaluation (Refs. 1 and 2) (SPACE) electrical power systems code, and SEP trajectory simulation tools developed at NASA Glenn Research Center.

\section{SUBJECT TERMS}

Solar electric propulsion; Attitude control; Solar arrays

\section{SECURITY CLASSIFICATION OF:}

a. REPORT

$\mathrm{U}$

b. ABSTRACT

$\mathrm{U}$

17. LIMITATION OF
ABSTRACT
UU

18. NUMBER
OF
PAGES
15

19a. NAME OF RESPONSIBLE PERSON STI Help Desk (email:help@sti.nasa.gov) 19b. TELEPHONE NUMBER (include area code) 443-757-5802 
